\title{
Penerapan Teknologi Tepat Guna Mesin Pengepres Sampah Plastik Sebagai Bahan Baku Daur Ulang
}

\author{
Muharsono, Sri Sutrismi, Desi Rahmawati, Marlena \\ Universitas Tulungagung \\ muharsono212@gmail.com trismi62@yahoo.com \\ desirahmawati.unita@gmail.com”cahayoe.n42@gmail.com
}

\begin{abstract}
The people of Sobontoro Boyolangu and Blumbang in district Campurdarat have a very good concern to manage the plastic waste. Their activities aim to help government create the healthy environment. They plan to build the community which is free from the adverse and dangerous effects of plastic waste. The community has formed a Bank of plastic waste to collect plastic waste for many years. What they have done brought the positive things. The plastic waste which was initially scattered around their house complex collected and pressed to reduce the volume of waste. The nice packed and pressed plastic waste can be more valuable and useful as raw material for recycling plastic products with the help of appropriate technology to be implemented in the community. The problems faced by the Bank of plastic waste relating with the insufficient knowledge about the harmful impact of plastic waste on the environment. The next issue deals with the absence of the appropriate technology to press the plastic waste for the sake of the efficiency in the case of the storage of plastic waste and in the distributing the plastic waste to the factory where the waste will be recycled. The method of carrying out the PPTTG activity involves stakeholders, the public and students. The outputs produced are products (the pressing machines of plastic waste), articles published in national journals, the videos, publications in electronic media and intellectual property right (industrial design and copyright).
\end{abstract}

Keywords : PPTTG Application; Plastic Waste Press Machine

\begin{abstract}
Abstrak
Masyarakat Desa Sobontoro Kecamatan Boyolangu dan Desa Campurdarat Kecamatan Campurdarat memiliki kepedulian terhadap pengelolaan sampah plastik dalam mewujudkan lingkungan yang sehat, bebas dari dampak buruk sampah plastik. Masyarakat membentuk kelompok Bank Sampah untuk mengepul limbah plastik sehingga plastik yang awalnya berserakan, dikumpulkan dan dipress untuk mengurangi volume sampah kemudian dimanfaatkan sebagai bahan baku daur ulang produk yang terbuat dari plastik dengan bantuan Teknologi Tepat Guna untuk diimplementasikan pada masyarakat. Permasalahannya, pengetahuan tentang dampak limbah plastik terhadap lingkungan masih terbatas dan belum memiliki teknologi tepat guna mesin pengepress sampah plastic agar efisiensi tempat dan menambah volume pengepulan sampah plastik sehingga dapat menambah pendapatan serta menyediakan lapangan kerja. Metode pelaksanan kegiatan melibatkan pemangku kepentingan, masyarakat dan mahasiswa. Luaran yang dihasilkan adalah produk (mesin pengepres sampah), artikel yang di muat di jurnal nasional, video kegiatan, publikasi di media elektronik dan kekayaan intelektual (desain industri dan hak cipta).
\end{abstract}


Kata Kunci : Penerapan PPTTG; Mesin Pengepres Sampah Plastik

\section{A. PENDAHULUAN}

Kelompok bank sampah yang menjadi mitra yang diusulkan dalam hibah Program Penerapan Teknologi Tepat Guna (PPTTG) Penerapan Teknologi Tepat Guna mesin pengepres sampah plastik sebagai bahan baku daur ulang plastik adalah Bank Smapah Mandiri dan Bank Sampah Kanigoro. Justifikasi penetapan ke dua mitra tersebut adalah mereka sangat peduli terhadap pengelolaan sampah plastic dan gigih sebagai pejuang lingkungan bebas sampah plastik.

Indikator spirit yang kuat untuk mewujudkan lingkungan bebas sampah terbaca ketika sebagian besar kelompok sampah di kabupaten Tulungagung menghentikan kegiatan karena berbagai sebab misalnya mereka tidak memiliki lahan penyimpanan yang memadahi karena sampah plastik yang belum dipress perlu tempat yang luas. Alasan lain nya adalah ongkos kirim plastic yang belum dipress dengan uang yang diterima tidak sebanding. Di saat krisis adanya kelompok masyarakat yang peduli terhadp sampah plastik ke dua mitra tersebut tetap memilih profesi sebagi relawan sampah dengan cara menjadi pengepul sampah plastic yang berasal dari masyarakat sekita, sekolah atu instasi lainnya

Data empriris yang ada menunjukan di tingkat global, national dan local termasuk di kabupaten Tulungagung, propinsi Jawa timur, di Indonesia dalam kegiatan kehidupan sehari-hari manusia tidak terlepas dari penggunakan plastik. Penggunaan secara luas dikembangkan dan digunakan sejak abad ke-20 yang berkembang secara luar biasa. Alasan pemilih plastik karena ringan, kuat, mudah mendapatkannya. Plastik yang dipergunakan oleh kebanyakan masyarakat adalah polimer sintetik yang dibuat dari minyak bumi yang tidak mudah terurai di tanah. Untuk menguraikan sampah plastik itu sendiri membutuhkan kurang lebih 80 tahun agar dapat terdegradasi secara sempurna. Oleh karena itu penggunaan bahan plastik dapat dikatakan tidak bersahabat ataupun konservatif bagi lingkungan apabila digunakan tanpa menggunakan batasan tertentu.

Jumlah pemakaiannya dari waktu ke waktu semakin besar jumlahnya. Hal ini telah menimbulkan masalah lingkungan misalnya pencemaran tanah dan juga penyakit. Menyadari dampak negatif yang ditimbulkan limbah pastik diperlukan adanya pemecahan masalah tentang sampah plastik ini yang semakin lama semakin membahayakan lingkungan. Sampah plastik dapat dikelola sehingga memberikan bernilai ekonomi tinggi. Limbah plastik yang awalnya berserakan dikumpulkan dan dipress, nantinya bisa dipakai biji plastik Untuk mengurangi volume sampah, khususnya sampah plastik yang banyak berserakan di Kota Tulungagung. Sampah plastik selain dapat diolah menjadi energi pembangkit listrik Tenaga Uap dapat pula dimanfaatkan sebagai bahan baku daur ulang perkakas yang terbuat dari plastik dengan bantuan Teknologi Tepat Guna yang sangat memungkinkan untuk diimplementasikan pada masyarakat.

\section{Permasalahan Mitra}

a. Pengetahuan tentang dampak limbah plastik terhadap lingkungan masih terbatas.

b. Mitra belum memiliki teknologi tepat guna untuk mengepres sampah plastik dalam rangka menghemat lahan pengepulan dan kesesuaian volume dan ongkos 
kirim untuk meningkatkan pendapatan mereka dan menyediakan lapangan pekerjaan baru.

Solusi Yang Ditawarkan

a. Memberikan pengetahuan tentang Sampah dan Lingkungan

b. Memberikan pengetahuan dan ketrampilan memilah jenis sampah plastic

c. Menggunakan teknologi tepat guna utuk mengoperasikan mesin pengepress sampah plastik

B. METODE PELAKSANAAN

a. Pihak yang terlibat dalam kegiatan sosialisasi, koordinasi dan diskusi adalah mitra, bapak camat, kepala desa, calon peserta pelatihan untuk inventarisasi permasalahan-permasalahan yang ada serta mencari pemecahan masalah.

b. Metode dan tahapan pelaksanaan yaitu dengan merencanakan, menyusun, dan melaksanakan tahapan-tahapan kegiatan penggunaan teknologi tepat guna untuk proses daur ulang sampah plastik (sosialisasi, pelatihan-pelatihan terkait dengan pengelolaan sampah melaui proses daur ulang, uji coba/praktek).

c. Teknologi Tepat Guna yang digunakan untuk daur ulang sampah adalah mesin pengepres plastik.

d. Prosedur kerja mengacu pada standar operasional.

e. Mitra terlibat aktif dalam seluruh tahapan kegiatan PPTTG.

f. Mengevaluasi pelaksanaan kegiatan untuk memperoleh masukan dalam penyempurnaan program selanjutnya.

Terkait dengan masalah yang dihadapi mitra, metode pelaksanaan kegiatan ini melakukan pendekatan kemasyarakatan dengan cara melibatkan para kelompok bank sampah, pemangku kepentingan, masyarakat terlibat dalam berbagai tahapan kegiatan mulai dari perencanaan sampai evaluasi.

Partisipasi masyarakat sangat diperlukan dalam bentuk dukungan aktif dari peserta berdiskusi mengenai masalah yang di hadapai dan solusi yang akan dilakukan dalam pengelolaan sampah melalui daur ulang dengan menggunakan teknologi tepat guna.

Sedangkan evaluasi program nantinya dilakukan dengan menganalisis hasil kegiatan tersebut dengan mengidentifikasi capaian, kendala, faktor-faktor pendukung, dampak kegiatan. Sedangkan untuk menjaga keberlanjutan program dilakukan monitoring

\section{HASIL DAN PEMBAHASAN}

Pada bagian ini, pelaksana fasilitasi Program Penerapan Teknologi Tepat Guna (PPTG) Mesin Pengepres Sampah Plastik mendiskripsikan kegiatan pengabdian kepada masyarakat yang sudah dilakukan dengan anggaran dana 100\% dari total kegiatan bertujuan untuk membantu masyarakat dan pemerintah mengelola limbah plastik untuk bisa dimanfaatkan oleh pihak yang berkompetensi melakukan pengelolaan sampah plastik serta membantu menciptakan lapangan kerja bagi ibu-ibu dan anak-anak usia kerja. Kegiatan PPTTG Mesin Pengepres Sampah Plastik 
dilaksanakan di Dusun Ngreco Desa Sobontoro Kecamatan Boyolangu dan Dusun Blumbang Desa Campurdarat Kecamatan Campurdarat Kabupaten Tulungagung Propinsi Jawa Timur. Kegiatan fasilitasi PPTTG mesin pengepres sampah plastik sangat diperlukan karena beberapa pertimbangan.

Pertama, daya tampung tempat pembuangan sampah (TPA) di Kabupaten Tulungagung sudah over load karena setiap hari terdapat 200 ton sampah basah dan kering. Kedua, keterbatasan tempat penampungan sampah plastik yang dimiliki oleh bank-bank sampah. Hal ini terjadi karena penyimpanan limbah plastik yang belum dipress memerlukan tempat yang luas. Ketiga, menyetorkan limbah plastik ke tempat daur ulang plastik tidak dapat memberikan untung banyak (karena alat angkutan nya terisi penuh namun beratnya/bobotnya sedikit). Hal yang demikian ini menyebabkan ongkos lebih besar/ mahal. Keempat, volume sampah plastik di Kabupaten Tulungagung perlu mendapat perhatikan pengelolaannya karena jika dibiarkan akan membuat lingkungan tercemari dengan bahan kimia berbahaya dan membahayakan kesehatan.

Di Tulungagung masing-masing desa memiliki bank sampah sehingga banyak pengumpul sampah yang menyetorkan limbah plastik ke bank sampah dan mereka membutuhkan cara bagaimana mengelola limbah plastik secara efisien dan murah namun juga dapat meningkatkan kesempatan lapangan kerja dan pendapatan keluarga.

Dengan penggunaan fasilitasi mesin pengepres sampah plastik dapat mendatangkan beberapa manfaat bagi masyarakat. Diantaranya adalah, dapat membantu mengurangi kiriman limbah plastik di tempat pembuangan akhir sampah, mencipatakan lingkungan yang bebas sampah, meringankan pekerjaan bank sampah dalam mengelola limbah plastik lebih efisien tempat dan menambah volume limbah yang ditangani.

Pelaksanaan kegiatan PPTTG melibatkan mahasiswa, masyarakat (nasabah) dan mitra bank sampah dengan cara melakukan sosialisasi dan musyawarah membuat komitmen pengelolaan sampah plastik dengan menggunakan mesin pengepres sampah plastik.

Berikut ini adalah kegiatan yang bisa dilaporkan:

Pengadaan Peralatan (mesin)
Tujuan
: Memfasilitasi PPTTG
Metode Pelaksanaan : Swakelola
Luaran
: Mesin Pengepres Sampah
Spesifikasi
a) Kapasitas 300 - $400 \mathrm{~kg}$ bahan baku/jam
b) Material : Mild Steel
c) Tekanan Pompa Hidrolik : 300 bar (2000 - 3000 ton $/ \mathrm{m}^{2}$ )
d) Penggerak : Motor Listrik $15 \mathrm{Hp}$

Sosialisasi Kegiatan
Waktu
: 01 Agustus 2019
Tempat
: Universitas Tulungagung
Tujuan
: Mengenal berbagai jenis limbah plastik, cara pemilahan, dan nilai jual dalam satuan ukur
Metode Pelaksanaan : Tutorial dan diskusi 
Peserta

Narasumbe

Prosedur Sosialisasi
: 1) Mahasiswa Universitas Tulungagung

2) Nasabah Bank Sampah Mandiri Desa Sobontoro

3) Bank Sampah Kanigoro Desa Campurdarat

4) Masyarakat (Ibu-Ibu rumah Tangga)

1) Bpk. Drs. Agus Prijanto (DLH Kab. Tulungagung)

2) Ketua Pelaksana PPTTGG Universitas Tulungagung

a) Persiapan/ perencanaan (sarana dan prasarana)

b) Pelaksanaan: (1) Instruktur menjelaskan pentingnya manajemen sampah, (2) Instruktur menjelaskan bagaimana menjadikan sampah mempunyai nilai ekonomis yang bisa membantu pendapatan keluarga sekaligus menciptakan lapangan pekerjaan bagi ibu-ibu rumah tangga dan anak pada usia kerja dan ibu-ibu rumah tangga.

c) Evaluasi (kuis lisan)

Pelatihan

Waktu Pelaksanaan : 08 Agustus 2019

Tempat Pelaksana : Bank Sampah Kanigoro Dsn. Ngreco Desa Sobontoro Kecamatan Boyolangu, Kabupaten Tulungagung

Tujuan : Mempraktekkan cara memilah jenis sampah dan cara menggunakan mesin pengepres sampah

Metode : Simulasi

Peserta : 1) Mahasiswa Universitas Tulungagung

2) Nasabah Bank Sampah Mandiri Desa Sobontoro

3) Nasabah Bank Sampah Kanigoro Desa Campurdarat

4) Masyarakat (Ibu-Ibu rumah Tangga)

Narasumber $\quad$ : Bpk. Suroso, SE (DLH Kab. Tulungagung)

Prosedur Pelatihan :a) Persiapan/ perencanaan (sarana dan prasarana)

b) Pelaksanaan: (1) Instruktur menjelaskan bagaimana memilah sampah sesuai dengan jenis nya, (2) Instruktur menjelaskan bagaimana menggunakan mesin pengepres sampah (simulasi)

c) Evaluasi (kuis lisan)

Uji Coba I

Waktu Pelaksanaan : 03 September 2019

Tempat Pelaksanaan : Bank Sampah Kanigoro Dsn. Ngreco Desa Sobontoro Kecamatan Boyolangu, Kab. Tulungagung

Tujuan : Mengetahui apakah spesifikasi alat (mesin pengepres sampah) dan rangkaiannya bisa berfungsi sebagaimana mestinya

Metode : Praktek

Peserta : 1) Mahasiswa Universitas Tulungagung

2) Nasabah Bank Sampah Mandiri Desa Sobontoro

3) Bank Sampah Kanigoro Desa Campurdarat

4) Masyarakat (Ibu-Ibu rumah Tangga)

Narasumber : Bpk. Sunaryo

Prosedur Uji Coba I 
a) Persiapan/ perencanaan (sarana dan prasarana)

b) Pelaksanaan:

1) Instruktur menjelaskan spesifikasi dan bagian-bagian alat (mesin pengepres), fungsi dan cara penggunaannya

2) Instruktur memberikan contoh bagaimana menggunakan mesin pengepres sampah

3) Peserta menerapkan skill yang di berikan oleh instruktur menggunakan mesin pengepres sampah (sampah plastik yang sudah dipilah sesuai dengan jenisnya di timbang lalu di masukkan karung kemudian di tuang kedalam box mesin lalu di press, hasil press keluar dalam keadaan rapi)

c) Evaluasi (Tanya jawab)

\section{Uji Coba II}

Waktu Pelaksanaan : 03 Desember 2019

Tempat Pelaksana : Bank Sampah Kanigoro Dsn. Ngreco Desa Sobontoro Kecamatan Boyolangu, Kabupaten Tulungagung

Tujuan : Mengetahui apakah spesifikasi alat (mesin pengepres sampah) dan rangkaiannya bisa berfungsi sebagaimana mestinya

Metode Pelaksanaan: Praktek

Peserta : 1) Mahasiswa Universitas Tulungagung

2) Nasabah Bank Sampah Mandiri Desa Sobontoro

3) Bank Sampah Kanigoro Desa Campurdarat

4) Masyarakat (Ibu-Ibu rumah Tangga)

Narasumber

$$
\text { : Bpk. Sunaryo }
$$

\section{Prosedur Uji Coba II}

a) Persiapan/ perencanaan (sarana dan prasarana)

b) Pelaksanaan:

1) Instruktur menjelaskan spesifikasi dan bagian-bagian alat (mesin pengepres), fungsi dan cara penggunaannya

2) Instruktur memberikan contoh bagaimana menggunakan mesin pengepres sampah

3) Peserta menerapkan skill yang di berikan oleh instruktur menggunakan mesin pengepres sampah (sampah plastik yang sudah dipilah sesuai dengan jenisnya di timbang lalu di masukkan karung kemudian di tuang kedalam box mesin lalu di press, hasil press keluar dalam keadaan rapi)

c) Evaluasi (Tanya jawab)

\section{PENUTUP}

Simpulan

Ada beberapa hal yang bisa dijelaskan pada bagian kesimpulan setelah program fasilitasi kegiatan PPTTG dilaksanakan dengan dana hibah Tahun Anggaran 2019 di Dusun Ngreco, Desa Sobontoro dan Dusun Blumbang Desa Campurdarat Kabupaten Tulungagung. Kesimpulan antara lain, manfaat yang didapat oleh dosen 
sebagai pelaksana kegiatan pengabdian kepada masyarakat adalah bisa melaksanakan tugas fungsional tridarma dosen yang menjadi kewajibannya untuk berkontribusi berpartisipasi dalam akselerasi pembangun masyarakat.

\section{Saran Dan Rekomendasi}

Sedangkan hal positif yang didapat oleh institusi, kegiatan pengabdian kepada masyarakat dapat menjadi media untuk bersosialisasi baik bagi individu sebagai tenaga pendidik yang berkewajiban melakukan pengabdian masyarakat maupun institusi dengan masyarakat agar lebih mengenal profile masing-masing. Mengetahui profile lembaga Perguruan Tinggi tempat dimana dosen selaku pelaksana kegiatan pengabdian kepada masyarakat sama pentingnya mengenali profile masyarakat untuk tujuan identifikasi masalah atau kebutuhan yang mungkin bisa dibantu jalan keluarnya. Bagi mitra, mereka mendapatkan pengetahuan, ketrampilan dan produk mesin pengepres plastik.

\section{E. DAFTAR PUSTAKA}

A.B. Glanvill and E.N. Denton. 1995. Injection Mould Design Fundamentals. Industrial Press INC. 200 Madison Aveneu New York.

Donald V Rosato, Dominick V Rosato. 1995. Injection Molding Handbook. Chapman and Hall. New York.

Georg Menges, Paul Mohren. 1997. How to Make Injection Molds. HanserPublisher. Munich Vienna New York Barcelona.

Herbert Rees. 1995. Mold Engineering. Hanser/Gardner Inc. Cincinnati.

H. Domininghaus. 1993. Plastics foe Engineers. Hanser Publishers. Munich. Vienna. New York. Barcelona.

Isnardiyanti, Sri. 2006. Kimia SMA Kelas III. Solo: Shindunata.

Jawa Pos. 20 Mei, 2008. Pasokan Batu Bara Untuk PLTU Menipis, Jawa Pos, hlm. 5 $\& 12$.

Keenan, CW. Kleinefelter, DC. Wood, JH. 1980. General College Chemistry, Harper \& Row, Publisher, Inc.

Malang Pos. 05 April, 2007. Timbunan Sampah Plastik di TPA Malang, Malang Pos, hlm. 2.

Ronald. J. Baird. 1986. Industrial Plastik. The Goodheart -Willcox Company. Inc. New York. 
http://yupazq.blogspot.com/2012/07/jenis-jenis-plastik-yang-dapat-didaur.html\#ixzz602KfChg0

http://yupazq.blogspot.com/2012/07/jenis-jenis-plastik-yang-dapat-didaur.html\#ixzz60209Ljmv

http://yupazq.blogspot.com/2012/07/jenis-jenis-plastik-yang-dapat-didaur.html\#ixzz602O14skI 